\title{
Arsenic Trioxide as a Radiation Sensitizer for 131I-Metaiodobenzylguanidine Therapy: Results of a Phase II Study
}

\author{
Shakeel Modak ${ }^{1}$, Pat Zanzonico ${ }^{2}$, Jorge A. Carrasquillo ${ }^{3}$, Brian H. Kushner ${ }^{1}$, Kim Kramer ${ }^{1}$, Nai-Kong V. Cheung ${ }^{1}$, \\ Steven M. Larson ${ }^{3}$, and Neeta Pandit-Taskar ${ }^{3}$ \\ ${ }^{1}$ Department of Pediatrics, Memorial Sloan Kettering Cancer Center, New York, New York; ${ }^{2}$ Department of Medical Physics, \\ Memorial Sloan Kettering Cancer Center, New York, New York; and ${ }^{3}$ Molecular Imaging and Therapy Service, Department of \\ Radiology, Memorial Sloan Kettering Cancer Center, New York, New York
}

Arsenic trioxide has in vitro and in vivo radiosensitizing properties. We hypothesized that arsenic trioxide would enhance the efficacy of the targeted radiotherapeutic agent ${ }^{131}$ I-metaiodobenzylguanidine (131/-MIBG) and tested the combination in a phase II clinical trial. Methods: Patients with recurrent or refractory stage 4 neuroblastoma or metastatic paraganglioma/pheochromocytoma (MP) were treated using an institutional review board-approved protocol (Clinicaltrials.gov identifier NCT00107289). The planned treatment was ${ }^{131} \mathrm{I}-\mathrm{MIBG}$ (444 or $666 \mathrm{MBq} / \mathrm{kg}$ ) intravenously on day 1 plus arsenic trioxide $\left(0.15\right.$ or $\left.0.25 \mathrm{mg} / \mathrm{m}^{2}\right)$ intravenously on days $6-10$ and $13-17$. Toxicity was evaluated using National Cancer Institute Common Toxicity Criteria, version 3.0. Response was assessed by International Neuroblastoma Response Criteria or (for MP) by changes in 123/-MIBG or PET scans. Results: Twenty-one patients were treated: 19 with neuroblastoma and 2 with MP. Fourteen patients received ${ }^{131} \mathrm{I}-\mathrm{MIBG}$ and arsenic trioxide, both at maximal dosages; 2 patients received a $444 \mathrm{MBq} / \mathrm{kg}$ dose of ${ }^{131} \mathrm{I}-\mathrm{MIBG}$ plus a $0.15 \mathrm{mg} / \mathrm{kg}$ dose of arsenic trioxide; and 3 patients received a $666 \mathrm{MBq} / \mathrm{kg}$ dose of ${ }^{131}$ IMIBG plus a $0.15 \mathrm{mg} / \mathrm{kg}$ dose of arsenic trioxide. One did not receive arsenic trioxide because of transient central line-induced cardiac arrhythmia, and another received only 6 of 10 planned doses of arsenic trioxide because of grade 3 diarrhea and vomiting with concurrent grade 3 hypokalemia and hyponatremia. Nineteen patients experienced myelosuppression higher than grade 2, most frequently thrombocytopenia $(n=18)$, though none required autologous stem cell rescue. Twelve of 13 evaluable patients experienced hyperamylasemia higher than grade 2 from transient sialoadenitis. By International Neuroblastoma Response Criteria, 12 neuroblastoma patients had no response and 7 had progressive disease, including 6 of 8 entering the study with progressive disease. Objective improvements in semiquantitative ${ }^{131}$ I-MIBG scores were observed in 6 patients. No response was seen in MP. Seventeen of 19 neuroblastoma patients continued on further chemotherapy or immunotherapy. Mean 5-year overall survival $( \pm S D)$ for neuroblastoma was $37 \% \pm$ $11 \%$. Mean absorbed dose of ${ }^{131} \mathrm{I}-\mathrm{MIBG}$ to blood was 0.134 cGy/MBq, well below myeloablative levels in all patients. Conclusion: ${ }^{131} \mid-$ MIBG plus arsenic trioxide was well tolerated, with an adverse event profile similar to that of ${ }^{131} \mathrm{I}-\mathrm{MIBG}$ therapy alone. The addition of arsenic trioxide to ${ }^{131} \mathrm{I}-\mathrm{MIBG}$ did not significantly improve re-

Received Jun. 3, 2015; revision accepted Oct. 13, 2015.

For correspondence or reprints contact: Shakeel Modak, Department of Pediatrics, Memorial Sloan Kettering Cancer Center, 1275 York Ave., New York, NY 10065.

E-mail: modaks@mskcc.org

Published online Jan. 7, 2016.

COPYRIGHT (C) 2016 by the Society of Nuclear Medicine and Molecular Imaging, Inc. sponse rates when compared with historical data with ${ }^{131}$ I-MIBG alone.

Key Words: radiosensitization; neuroblastoma; malignant pheochromocytoma/paraganglioma; MIBG therapy

J Nucl Med 2016; 57:231-237

DOI: 10.2967/jnumed.115.161752

M etaiodobenzylguanidine (MIBG) is a guanethidine analog that is taken up via the noradrenaline transporter by neuroendocrine malignancies arising from sympathetic neuronal precursors (1). These neoplasms include neuroblastoma, the most common solid tumor of childhood, which is often metastatic at diagnosis, and malignant paraganglioma/pheochromocytoma (MP). Recent therapeutic advances have led to modest improvements in the outcome of patients with high-risk neuroblastoma; however, approximately half the patients with stage 4 neuroblastoma and a much higher proportion of patients with relapsed or chemorefractory disease succumb to it (2). ${ }^{123}$ I-MIBG scans are the gold standard for staging of neuroblastoma, with more than $90 \%$ of patients having ${ }^{123} \mathrm{I}-\mathrm{MIBG}$-avid disease (3). ${ }^{131} \mathrm{I}-\mathrm{MIBG}$ therapy has undergone several trials for neuroblastoma over more than 3 decades (4). A dose of $666 \mathrm{MBq} / \mathrm{kg}$ is generally accepted as the maximum per administration (5). The consensus is that treatment, although active against resistant neuroblastoma, especially for disease palliation (6), is not curative. Reported response rates have been no more than $30 \%$ even when relatively nonstringent criteria were used to evaluate disease response (4). Similarly, a response in patients with MP is uncommon, although ${ }^{131} \mathrm{I}-\mathrm{MIBG}$ therapy is associated with symptomatic relief and hormonal response (7).

The cause of suboptimal response has not been well characterized and is likely multifactorial (8). Strategies to enhance the clinical response to ${ }^{131}$ I-MIBG therapy have included increasing the amount (i.e., administered activity) and number of ${ }^{131} \mathrm{I}-\mathrm{MIBG}$ doses $(5,9)$, combining them with myeloablative chemotherapy and autologous stem cell transplantation (10), and adding radiation-sensitizing agents $(11,12)$. Preclinical mechanistic justifications for the clinical use of radiosensitizers in combination with ${ }^{131}$ I-MIBG therapy include enhancement of noradrenaline transporter expression or activity, such as through topoisomerase inhibitors, and a synergistic effect on inhibition of radiation-induced DNA repair, such as through vorinostat $(13,14)$. 
Arsenic trioxide is an apoptotic agent that acts via cytotoxic pathways distinct from conventional chemotherapeutic agents and suppresses growth of neuroblastoma xenografts $(15,16)$. Its radiationsensitizing effects have been demonstrated in preclinical models of several tumors, including fibrosarcoma $(17)$ and glioma $(18,19)$. The combination of ${ }^{89} \mathrm{Sr}$ and arsenic trioxide showed beneficial killing of MCF7 cells (20). In other preclinical experiments, arsenic trioxide synergized with the radioiodinated anti-GD2 monoclonal antibody ${ }^{131} \mathrm{I}-3 \mathrm{~F} 8$ against neuroblastoma xenografts (Modak et al. unpublished data 2003). Clinical evidence suggesting a radiosensitizing effect for arsenic trioxide is derived from reports of response to concurrent arsenic trioxide and external-beam radiotherapy in chemoradioresistant cutaneous breast cancer (21) and extramedullary acute promyelocytic leukemia (22) and from a report of severe radiation recall in a patient previously treated with arsenic trioxide (23). Arsenic trioxide has been established as a highly effective agent for the treatment of acute promyelocytic leukemia in adults and children, and the combination of arsenic trioxide and all-trans retinoic acid may reduce the need for subsequent anthracycline therapy (24). In children with acute leukemia and infiltrating astrocytoma treated with arsenic trioxide in phase I studies, arsenic trioxide was well tolerated, with adverse events similar to those encountered in adults: vomiting, diarrhea, and QTc prolongation $(25,26)$, with a recommended dosage of $0.15 \mathrm{mg} / \mathrm{kg} / \mathrm{d}$. However, in children with neuroblastoma and other solid tumors treated with arsenic trioxide as a single agent, doselimiting toxicity was not encountered even at $0.25 \mathrm{mg} / \mathrm{kg} / \mathrm{d}$ when serum electrolytes were optimally maintained (clinicaltrials.gov identifier NCT00024258). On the basis of these preclinical and clinical data, and the nonoverlapping toxicities of the two agents, we hypothesized that arsenic trioxide would act as a radiosensitizer for ${ }^{131} \mathrm{I}$-MIBG therapy, and we conducted a pilot phase II study (NCT00107289) in patients with relapsed or refractory neuroblastoma and MP, the results of which we report below.

\section{MATERIALS AND METHODS}

\section{Patient Selection}

Eligible patients were those older than $1 \mathrm{y}$ with high-risk neuroblastoma (stage 4 disease diagnosed at $>18$ mo old or $M Y C N$-amplified tumor of $\geq$ stage 3 at any age) and a history of progressive disease or chemoresistance, and those younger than $21 \mathrm{y}$ with MP. The presence of ${ }^{123}$ I-MIBG-avid evaluable or measurable disease $3 \mathrm{wk}$ or more after completion of systemic therapy was required for protocol entry. Other salient eligibility criteria included the availability of at least $2 \times 10^{6}$ $\mathrm{CD}^{+}{ }^{+}$autologous hematopoietic stem cells (cryopreserved for reinfusion) per kilogram of body weight, ability and willingness to comply with radiation safety procedures, and lack of life-threatening infections and nonhematologic toxicity higher than grade 2 (including renal, cardiac, hepatic, pulmonary, gastrointestinal, and neurologic) according to version 3.0 of the Common Toxicity Criteria of the National Cancer Institute.

\section{Study Design}

The protocol was approved by the institutional review board of Memorial Sloan Kettering Cancer Center. Written informed consent was obtained from patients or their guardians. Since this was the first study of this novel combination, it was decided not to proceed with maximal doses unless no serious adverse events were encountered in a pilot group of 5 patients who were treated with reduced doses of the therapeutic agents. Treatment consisted of a single intravenous dose of ${ }^{131} \mathrm{I}-\mathrm{MIBG}(444[12 \mathrm{mCi} / \mathrm{kg}]$ or $666 \mathrm{MBq} / \mathrm{kg}[18 \mathrm{mCi} / \mathrm{kg}])$ administered over $1 \mathrm{~h}$ on day 0 followed by intravenous arsenic trioxide as a single daily dose of $0.15 \mathrm{mg} / \mathrm{kg}$ or $0.25 \mathrm{mg} / \mathrm{kg}$ administered over $2 \mathrm{~h}$ on days 5 through 9 and days 12 through 16. ${ }^{131}$ I-MIBG was radiolabeled at Nuclear Diagnostic Products and had a confirmed radiochemical purity of at least $99 \%$ within $4 \mathrm{~h}$ before injection. Toxicities were graded with Common Toxicity Criteria, version 3.0, and response for neuroblastoma patients was assessed 4-6 wk after ${ }^{131}$ I-MIBG therapy, with International Neuroblastoma Response Criteria (27) modified to include ${ }^{123}$ I-MIBG scans. Response was classified as complete remission (no evidence of disease including in bone marrow), very good partial response (primary mass reduced by $>90 \%$, no evidence of distant disease and normal catecholamines), partial remission ( $>50 \%$ decrease in measurable disease, number of positive bone sites decreased by $50 \%$, and $\leq 1$ positive bone marrow site), mixed response (no new lesions, $>50 \%$ decrease in any measurable lesion and $<50 \%$ decrease in any other), no response ( $<50 \%$ decrease but $<25 \%$ increase in any existing lesion), and progressive disease (new lesion or $>25 \%$ increase in an existing lesion). Patients with no response or mixed response were categorized as having stable disease. For patients with MP, RECIST criteria were used if there was measurable disease. For both groups of patients, objective changes in ${ }^{123}$ I-MIBG scans were recorded using the semiquantitative Curie score $(28,29)$. Relative ${ }^{123}$ I-MIBG score was calculated by dividing Curie score after treatment by prior Curie score. Dosimetry and pharmacokinetic data were obtained using serial whole-body imaging and peripheral venous blood specimens; typically, up to 10 blood samples were obtained from less than $1 \mathrm{~h}$ after to $10 \mathrm{~d}$ after ${ }^{131} \mathrm{I}-\mathrm{MIBG}$ injection. The activity concentrations in weighed aliquots of blood were measured in a scintillation well counter calibrated for ${ }^{131} \mathrm{I}$, fit to a biexponential time-activity concentration function, and analytically integrated to yield the area under the curve. The resulting cumulated activity concentration was then multiplied by the equilibrium dose constant for the ${ }^{131} \mathrm{I} \beta$-rays, $\Delta_{\beta}=0.405 \mathrm{~g}$-cGy/37 MBq, to yield the mean absorbed dose to blood. Implicit in the foregoing absorbed-dose calculation were the standard assumptions that the ${ }^{131}$ I $\beta$-rays are completely absorbed in blood and the contribution of the highly penetrating $\gamma$-rays was negligible.

\section{Safety Precautions}

Thyroid protection included oral administration of a saturated solution of potassium iodide (5-7 drops [250-330 mg] thrice daily) and liothyronine (25-75 $\mu \mathrm{g}$ once daily) starting about $7 \mathrm{~d}$ before ${ }^{131} \mathrm{I}-\mathrm{MIBG}$ and continuing for 14 and $42 \mathrm{~d}$, respectively, after ${ }^{131} \mathrm{I}-\mathrm{MIBG}$ infusion. ${ }^{131}$ I-MIBG was administered on an in-patient basis, only after demonstration of thyroid suppression as documented by subnormal thyroidstimulating hormone levels. Urinary bladder protection was provided by maintenance of a Foley catheter for at least $72 \mathrm{~h}$ after ${ }^{131} \mathrm{I}-\mathrm{MIBG}$ therapy. Radiation safety precautions were followed to minimize exposure to family, public, and staff, including use of isolation rooms and rolling lead shields. Patients were discharged only after the whole-body dose rate had fallen to less than $7 \mathrm{cGy} / \mathrm{h}$ at a distance of $1 \mathrm{~m}$. Arsenic trioxide was administered only if the absolute QT interval was more than $500 \mathrm{~ms}$. During arsenic trioxide therapy, serum potassium and magnesium levels were maintained at more than $4 \mathrm{mEq} / \mathrm{dL}$ and more than $1.8 \mathrm{mg} / \mathrm{dL}$, respectively. Filgrastim was given to maintain an absolute neutrophil count of more than $500 / \mu \mathrm{L}$. Platelet and red blood cell transfusions were administered as clinically indicated. Patients were required to receive autologous stem cell rescue (ASCR) if their absolute neutrophil count remained less than $500 / \mu \mathrm{L}$ for more than $14 \mathrm{~d}$ despite filgrastim, if they required platelet transfusions more than twice weekly for $4 \mathrm{wk}$ after ${ }^{131} \mathrm{I}-$ MIBG therapy, or if they experienced life-threatening infection in the setting of neutropenia.

\section{Biostatistical Considerations}

Since this was the first study of the novel combination of ${ }^{131} \mathrm{I}-$ MIBG therapy and arsenic trioxide, we instituted early-stopping rules for unacceptable toxicity: therapy was stopped early if at least 4 of the first 10 patients or 6 patients at any time experienced a nonhematologic 
toxic event higher than grade 3 or if at least 3 patients experienced graft failure after ASCR. The primary endpoint was efficacy of the combination as assessed by response. We proposed declaring treatment effective if the probability of response was at least 0.4. A Simon 2-stage design that differentiated between response rates of 0.4 and 0.65 was used, with plans to treat 13 evaluable neuroblastoma patients at maximal doses of ${ }^{131} \mathrm{I}-\mathrm{MIBG}$ and arsenic trioxide in the first phase and to add 15 neuroblastoma patients only if more than 5 responses (complete remission plus partial remission) were observed in the first cohort. The efficacy rule did not apply to patients with MP. Survival was analyzed using Kaplan Meier and log-rank tests (SPSS).

\section{RESULTS}

\section{Patient Demographics}

Twenty-one patients (12 male and 9 female, with a median age of 7.8 y and a range of 2-30.4 y) were treated from 2005 to 2008 : 19 with neuroblastoma, including one treated as per protocol after compassionate approval from the Memorial Sloan Kettering Cancer Center institutional review board and two with MP (Table 1). Two patients received a $444 \mathrm{MBq} / \mathrm{kg}$ dose of ${ }^{131} \mathrm{I}-\mathrm{MIBG}$ plus a $0.15 \mathrm{mg} / \mathrm{kg}$ dose of arsenic trioxide and 3 received a $666 \mathrm{MBq} / \mathrm{kg}$ dose of ${ }^{131} \mathrm{I}$-MIBG plus a $0.15 \mathrm{mg} / \mathrm{kg}$ dose of arsenic trioxide. Fourteen patients (including one treated as per protocol) received ${ }^{131} \mathrm{I}-\mathrm{MIBG}$ plus arsenic trioxide at maximal dosages of $666 \mathrm{MBq} / \mathrm{kg}$ plus $0.25 \mathrm{mg} / \mathrm{kg}$, respectively.

Neuroblastoma patients had undergone heavy prior treatment, with a median of 3 previous therapeutic regimens; 15 patients were treated after prior relapse (median, 2 prior relapses), and 4 had chemorefractory metastatic disease. Fourteen had stage 4 disease at diagnosis, whereas one (patient 8; Table 1) was diagnosed with stage $2 \mathrm{~B}$ neuroblastoma and then relapsed with metastatic disease before study entry. Both MP patients had germline mutations in the succinyl dehydrogenase B gene, had multiple skeletal metastatic sites ( ${ }^{123}$ I-MIBG Curie scores of 7 and 9,

TABLE 1

Patient Demographics, Response, and Survival

\begin{tabular}{|c|c|c|c|c|c|c|c|c|c|c|c|}
\hline \multirow[b]{2}{*}{$\begin{array}{l}\text { Patient } \\
\text { no. }\end{array}$} & \multirow[b]{2}{*}{$\begin{array}{c}\text { Age at } \\
\text { treatment }(y)\end{array}$} & \multirow[b]{2}{*}{$\begin{array}{l}\text { MYCN } \\
\text { status }\end{array}$} & \multirow[b]{2}{*}{$\begin{array}{l}\text { No. of } \\
\text { prior } \\
\text { relapses }\end{array}$} & \multirow[b]{2}{*}{$\begin{array}{l}\text { Prestudy } \\
\text { status }\end{array}$} & \multirow[b]{2}{*}{$\begin{array}{c}\text { Prestudy } \\
\text { 123I-MIBG } \\
\text { score }\end{array}$} & \multicolumn{2}{|c|}{ Dose administered } & \multicolumn{2}{|c|}{ Response } & \multicolumn{2}{|c|}{ Survival } \\
\hline & & & & & & $\begin{array}{c}\text { Actual } \\
\text { 131'I-MIBG } \\
(\mathrm{MBq} / \mathrm{kg})\end{array}$ & $\begin{array}{c}\text { Arsenic } \\
\text { trioxide } \\
(\mathrm{mg} / \mathrm{kg} / \mathrm{d})\end{array}$ & INRC & $\begin{array}{c}\text { Relative } \\
\text { 131I-MIBG } \\
\text { score }\end{array}$ & $\begin{array}{l}\text { Progression- } \\
\text { free survival } \\
\text { (mo) }\end{array}$ & $\begin{array}{l}\text { Overall } \\
\text { survival } \\
\text { (mo) }\end{array}$ \\
\hline \multicolumn{12}{|l|}{ MP } \\
\hline 1 & 9.8 & N/A & 1 & SD & 7 & 656.6 & 0.15 & N/A & 1.00 & $63.1^{*}$ & $63.1^{\star}$ \\
\hline 2 & 13.3 & N/A & 1 & SD & 9 & 668.4 & 0.15 & N/A & 1.00 & $100.2^{*}$ & $100.2^{*}$ \\
\hline \multicolumn{12}{|l|}{ NB } \\
\hline 3 & 9.2 & NA & 1 & SD & 13 & 444 & 0.15 & NR & 0.85 & $100.6^{\star}$ & $100.6^{*}$ \\
\hline 4 & 7.7 & NA & 0 & SD & 11 & 462.5 & 0.15 & NR & 1.00 & 79.2 & $99.0^{*}$ \\
\hline 5 & 9.9 & NA & 1 & SD & 8 & 673.2 & 0.15 & NR & 0.88 & $94.1^{*}$ & $94.1^{*}$ \\
\hline 6 & 6.0 & NA & 2 & PD & 6 & 669.7 & $0^{\dagger}$ & NR & 1.00 & 6.5 & 15.5 \\
\hline 7 & 2.0 & Ampl & 0 & SD & $2^{\ddagger}$ & 647.5 & 0.25 & NR & 1.00 & $91.8^{*}$ & $91.8^{*}$ \\
\hline 8 & 2.8 & NA & 1 & SD & 20 & 677.1 & 0.25 & NR & 1.00 & $83.3^{*}$ & $83.3^{*}$ \\
\hline 9 & 3.3 & Ampl & 2 & PD & $2^{\ddagger}$ & 662.3 & 0.25 & PD & 1.00 & 0.9 & 3.7 \\
\hline 10 & 4.7 & NA & 0 & SD & 14 & 632.7 & 0.25 & NR & 1.00 & $71.8^{*}$ & $71.8^{\star}$ \\
\hline 11 & 5.8 & NA & 5 & PD & $2^{\ddagger}$ & 662.3 & 0.25 & PD & 1.00 & 0.7 & 4.8 \\
\hline 12 & 6.1 & Ampl & 2 & PD & 21 & 691.9 & 0.25 & PD & 0.90 & 2.8 & 4.0 \\
\hline 13 & 6.1 & NA & 4 & PD & $2^{\ddagger}$ & 677.1 & 0.25 & PD & 1.00 & 1.4 & 8.7 \\
\hline 14 & 6.2 & Ampl & 3 & SD & 5 & 662.3 & 0.25 & PD & 1.00 & 6.5 & 14.4 \\
\hline 15 & 7.8 & NA & 4 & SD & 13 & 636.4 & 0.25 & NR & 1.00 & 3.7 & 14.7 \\
\hline 16 & 8.3 & NA & 3 & SD & 21 & 658.6 & 0.25 & NR & 0.95 & 3.6 & 8.8 \\
\hline 17 & 8.4 & NA & 0 & SD & 9 & 684.5 & 0.25 & NR & 0.88 & $83.3^{*}$ & $83.3^{*}$ \\
\hline 18 & 8.4 & NA & 1 & PD & 10 & 654.9 & 0.25 & PD & 1.30 & 1.2 & 27.2 \\
\hline 19 & 8.7 & NA & 3 & PD & 6 & 688.2 & 0.25 & PD & 1.50 & 1.2 & 9.8 \\
\hline 20 & 15.2 & NA & 1 & SD & 9 & 647.5 & 0.25 & NR & 1.00 & 6.2 & 23.7 \\
\hline 21 & 30.4 & NA & 2 & PD & 8 & 658.6 & $0.25^{\S}$ & NR & 0.63 & 11.5 & 61.6 \\
\hline
\end{tabular}

${ }^{*}$ Continue to be progression-free.

${ }^{\dagger}$ Arsenic trioxide not administered because of central-line-induced arrhythmia.

${ }^{\ddagger}$ MIBG-avid soft-tissue disease only.

${ }^{\S}$ Only 6 of 10 planned arsenic trioxide doses were administered because of diarrhea and electrolyte imbalance.

INRC = International Neuroblastoma Response Criteria; NB = neuroblastoma; N/A = not applicable; NA = not amplified; Ampl = amplified; SD = stable disease; $\mathrm{PD}=$ progressive disease; $\mathrm{NR}=$ no response. 
TABLE 2

Toxicity Related to Therapy

\begin{tabular}{|c|c|c|c|c|}
\hline \multirow[b]{2}{*}{ Toxicity } & \multicolumn{4}{|c|}{ Grade } \\
\hline & 1 & 2 & 3 & 4 \\
\hline \multicolumn{5}{|l|}{ Symptomatology } \\
\hline Diarrhea & 5 & 4 & 1 & 0 \\
\hline Vomiting & 8 & 7 & 1 & 0 \\
\hline Dry skin & 2 & 1 & 0 & 0 \\
\hline Headache & 0 & 1 & 0 & 0 \\
\hline Anorexia & 1 & 0 & 0 & 0 \\
\hline Pain (cheek) & 2 & 0 & 0 & 0 \\
\hline Dry mouth & 1 & 0 & 0 & 0 \\
\hline Fatigue & 1 & 0 & 0 & 0 \\
\hline \multicolumn{5}{|l|}{ Laboratory values } \\
\hline Anemia & 0 & 7 & 12 & 0 \\
\hline Neutropenia & 0 & 3 & 8 & 8 \\
\hline Thrombocytopenia & 1 & 2 & 3 & 15 \\
\hline Lymphopenia & 0 & 0 & 3 & 15 \\
\hline Hypokalemia & 6 & 2 & 1 & 0 \\
\hline Hyponatremia & 7 & 0 & 1 & 0 \\
\hline Hypermagnesemia & 2 & 0 & 0 & 0 \\
\hline Elevated serum creatinine & 1 & 0 & 0 & 0 \\
\hline Elevated serum AST & 7 & 0 & 0 & 0 \\
\hline Elevated serum ALT & 9 & 0 & 0 & 0 \\
\hline Hyperbilirubinemia & 1 & 0 & 0 & 0 \\
\hline Hyperamylasemia* & 0 & 0 & 12 & 0 \\
\hline
\end{tabular}

*Serum amylase levels were measured in 13 patients.

$\mathrm{AST}=$ aspartate transaminase; $\mathrm{ALT}=$ alanine transaminase.

respectively), and had recurrent disease 2 and 7 mo after alkylatorbased chemotherapy. Most patients had a relatively high disease burden at entry, with a median $( \pm$ SD) Curie score of $9 \pm 5.9$ (range, 2-21).

\section{Toxicity}

Treatment was well tolerated in general, without mortality or severe morbidity (Table 2). None of the 5 patients treated with reduced doses experienced severe adverse events, and a further 14 patients received both agents at maximal doses. One patient (patient 6; Table 1) did not receive any arsenic trioxide because of the development of central line-related arrhythmia before commencing arsenic trioxide. A second patient developed arsenic trioxide-related grade 3 vomiting and diarrhea with accompanying grade 3 hypokalemia and hyponatremia and received only 6 of 10 planned doses of arsenic trioxide. Other expected toxicities higher than grade 2 were those that have previously been described with ${ }^{131} \mathrm{I}-\mathrm{MIBG}$ therapy $(9,30)$ and included neutropenia $(n=16$ patients), thrombocytopenia $(n=18)$, lymphopenia $(n=18)$, anemia $(n=12)$, and hyperamylasemia due to transient sialoadenitis $(n=12 / 13$ patients evaluated). No patient experienced febrile neutropenia or serious infection. All patients with thrombocytopenia received platelet transfusions. As defined in the protocol criteria, ASCR was not required for any patient. Thyroid-stimulating hormone levels assessed 3-6 mo after therapy were normal $(n=12)$.

\section{Pharmacokinetics, Dosimetry, and Targeting}

${ }^{123}$ I-MIBG in blood exhibited biphasic kinetics (evaluated in 16 patients), with an initial rapid component (87\% of the blood activity on average) having a mean biologic half-life of $1.37 \pm$ $1.41 \mathrm{~h}$ and a second slower component (13\% of the blood activity on average) having a biologic half-life of $28.1 \pm 5.62 \mathrm{~h}$. A typical blood time-activity curve is shown in Figure 1 . The absorbed dose to blood averaged $0.134 \pm 0.0928 \mathrm{cGy} / \mathrm{MBq}$, with a maximum of $0.354 \mathrm{cGy} / \mathrm{MBq}$. The total absorbed dose to blood was $46.0 \pm$ 25.0 cGy. Posttreatment ${ }^{131} \mathrm{I}$-MIBG $\gamma$-camera scanning was performed on 20 patients. All sites of disease detected by pretherapy ${ }^{123}$ I-MIBG scans showed targeting with therapeutic ${ }^{131}$ I-MIBG. In addition, a significantly higher number of skeletal lesions were detected on post- ${ }^{131}$ I-MIBG therapy scans in all (neuroblastoma and MP) patients with skeletal disease $(n=17)$, with $3.3 \pm 1.6$ (range, $2-7)$ additional lesions noted $(P<0.05$ by $t$ testing for pretherapy vs. posttherapy ${ }^{123}$ I-MIBG scores). However, no extra lesions were detected in patients who had only soft-tissue disease $(n=3)$.

\section{Disease Response}

Neuroblastoma. Overall, no major response (complete remission plus partial remission) was observed in neuroblastoma patients (Table 1). Twelve patients had no response by International Neuroblastoma Response Criteria, and 7 had progressive disease. Of 8 patients with progressive disease at study entry, 6 had further progressive disease, whereas 10 of 11 patients with stable nonprogressing disease immediately before protocol therapy had no response to treatment. There was no reduction in measurable softtissue disease $(n=9)$ or in bone marrow neuroblastoma as assessed by histology $(n=6)$. Fifteen of 19 patients had ${ }^{123} \mathrm{I}-\mathrm{MIBG}-\mathrm{avid}$ skeletal metastases, and 4 of 19 had only ${ }^{123}$ I-MIBG-avid soft-tissue disease before therapy. Of 15 patients with skeletal disease, 9 had no change on ${ }^{123} \mathrm{I}-\mathrm{MIBG}$ scanning (relative ${ }^{123}$ I-MIBG score of 1) and 6 had an objective response on ${ }^{123}$ I-MIBG scanning but a relative ${ }^{123} \mathrm{I}-\mathrm{MIBG}$ score greater than 0.5 , thus not meeting the extended International Neuroblastoma Response Criteria for partial remission (Table 3 ). Three of the 4 patients with only

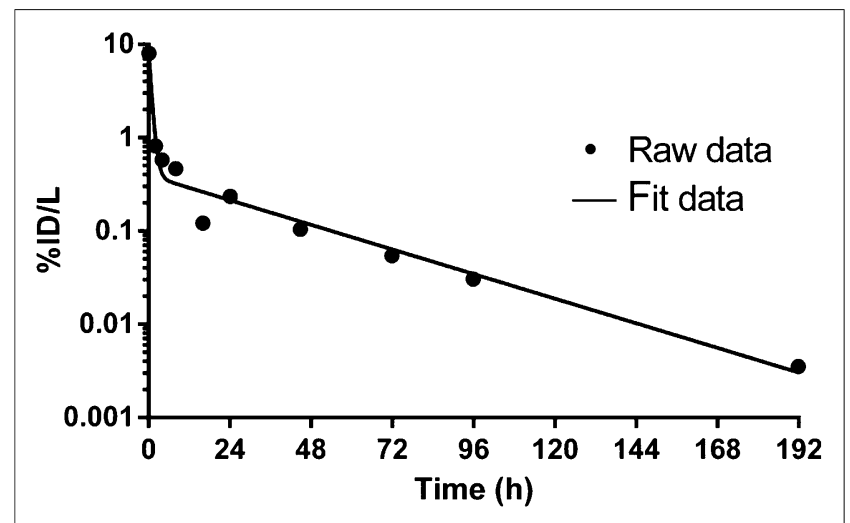

FIGURE 1. Typical 131/-MIBG blood time-activity concentration curve. Data points represent measured values and curve best-fit function, with initial component having zero-time intercept of $891.7 \mathrm{kBq}$ $(24.1 \mu \mathrm{Ci}) / \mathrm{mL}(94 \%$ of activity in blood) and biologic half-life of $1.88 \mathrm{~h}$ and second component having zero-time intercept of $55.5 \mathrm{kBq}(1.5$ $\mu \mathrm{Ci}) / \mathrm{mL}(6 \%$ of activity in blood) and biologic half-life of $23.9 \mathrm{~h}$. ID $=$ injected dose. 
TABLE 3

Objective Response Rates in Patients with Neuroblastoma

\begin{tabular}{cccc}
\hline Site of disease & $\begin{array}{c}\text { No. of } \\
\text { patients }\end{array}$ & $\begin{array}{c}\text { Objective } \\
\text { response }\end{array}$ & $\begin{array}{c}\text { Objective } \\
\text { response } \\
\text { rate }\end{array}$ \\
\hline Soft tissue & 9 & 0 & $0 \%$ \\
$\begin{array}{c}\text { Bone marrow } \\
\text { (by histology) }\end{array}$ & 6 & 0 & $0 \%$ \\
$\begin{array}{c}\text { Skeleton (by } \\
\text { 131I-MIBG } \\
\text { scan) }\end{array}$ & 15 & 6 & $40 \%$ \\
\hline
\end{tabular}

There were no major responses as assessed by International Neuroblastoma Response Criteria.

soft-tissue disease before therapy had progressive disease. Urine catecholamine levels were reduced in 4 of 7 patients with elevated levels.

MP. Both patients with MP had extensive skeletal disease ( ${ }^{123} \mathrm{I}-\mathrm{MIBG}$ scores of 7 and 9 , respectively), and one had measurable soft-tissue disease; neither had an objective response to therapy with ${ }^{131}$ I-MIBG plus arsenic trioxide. Urine normetanephrines decreased by $50 \%$ in one patient, whereas the other did not secrete metanephrines.

The study was terminated after the first phase since it did not meet the response criteria for continuation.

\section{Postprotocol Therapy and Survival}

Seventeen neuroblastoma patients went on to receive additional therapy for their residual or progressive disease after leaving the study. Although ASCR was not indicated for any patient during the study, 10 patients underwent ASCR after high-dose myelosuppressive (but nonmyeloablative) chemotherapy after completing the required protocol observations, and all patients engrafted after ASCR. Other postprotocol therapies included immunotherapy with the anti-GD2 monoclonal antibody 3F8 $(n=7)$. One patient had early progressive disease and did not receive any further therapy, whereas another did not receive any further therapy but is a long-term survivor at more than 91 mo after therapy despite having persistent ${ }^{123} \mathrm{I}-\mathrm{MIBG}-$ avid pancreatic disease. All patients were followed for late toxicities, none of which were observed. The contribution of ${ }^{131} \mathrm{I}-\mathrm{MIBG}$ plus arsenic trioxide in prolonging survival could not be evaluated. Five-year overall survival for neuroblastoma patients is $37 \% \pm 11 \%$, with 7 long-term survivors, all but one of whom (patient 17; Table 1) have residual disease. Patient 17 achieved complete remission after further therapies after ${ }^{131} \mathrm{I}-\mathrm{MIBG}$ and remains a long-term disease-free survivor. Median overall survival was $23.7 \pm 9.1 \mathrm{mo}$, and median time to progressive disease was $6.5 \pm 2$ mo. However, patients with progressive disease at study entry had a significantly worse survival $(P<0.001$ for overall and progression-free survival $)$ than those with stable disease before therapy, with a median overall and progression-free survival of $9.8 \pm 1$ and $1.4 \pm 0.3 \mathrm{mo}$, respectively. Both patients with MP survive with residual but progressionfree disease, at 63.1 and 100.2 mo after therapy. One was treated with a second dose of high-dose ${ }^{131}$ I-MIBG therapy without arsenic trioxide, whereas the other did not receive any postprotocol therapy.

\section{DISCUSSION}

The combination of high-dose ${ }^{131}$ I-MIBG therapy and arsenic trioxide, even at maximal doses, was well tolerated and had no significant unexpected toxicity. As anticipated with ${ }^{131} \mathrm{I}-\mathrm{MIBG}$ doses of at least $444 \mathrm{MBq} / \mathrm{kg}$, myelosuppression higher than grade 3 and requiring blood product support was encountered, though no patient developed serious infections or required inpatient admission after discharge after ${ }^{131} \mathrm{I}-\mathrm{MIBG}$ infusion. In only one patient did arsenic trioxide add significant toxicity. Neither ${ }^{131}$ I-MIBG nor arsenic trioxide had an effect on response or toxicity, with the only nonhematologic toxicity higher than grade 2 being observed in the patient who received 6 of ten $0.25 \mathrm{mg} / \mathrm{kg}$ doses of arsenic trioxide. Posttherapy scans showed excellent targeting of ${ }^{131} \mathrm{I}-\mathrm{MIBG}$ to lesions and, similar to previous reports (31), revealed lesions not detected on pretherapy ${ }^{123}$ I-MIBG scans. However, response rates for resistant neuroblastoma were not better than the historical data on single-agent high-dose ${ }^{131}$ I-MIBG, suggesting that arsenic trioxide did not have a radiosensitizing or other beneficial effect for ${ }^{131} \mathrm{I}-\mathrm{MIBG}$ therapy. Objective responses were not seen in the two MP patients.

Similar observations have been made for other radiosensitizers, though toxicity has generally been worse than that encountered with ${ }^{131}$ I-MIBG plus arsenic trioxide. Specifically, the addition of irinotecan and vincristine to ${ }^{131}$ I-MIBG therapy yielded response rates of $25 \%$ but with an increase in toxicity, whereas combination with vorinostat was associated with a response rate of $12 \%-17 \%$ $(12,32)$. The combination of ${ }^{131} \mathrm{I}-\mathrm{MIBG}$ therapy and myeloablative chemotherapy followed by autologous stem cell transplantation has been investigated by several groups. ${ }^{131}$ I-MIBG therapy followed by myeloablative chemotherapy with carboplatin, etoposide plus melphalan (10), or busulfan plus melphalan (33) was associated with significant toxicity, especially hepatic sinusoidal obstructive syndrome, without a response improvement in chemoresistant neuroblastoma (34). The contribution of ${ }^{131}$ I-MIBG therapy to response could not be defined, and there remains a need to optimize the use of ${ }^{131}$ I-MIBG therapy followed by myeloablative chemotherapy for patients with neuroblastoma. Small, nonrandomized studies have reported better response rates when ${ }^{131} \mathrm{I}-\mathrm{MIBG}$ therapy has been used in the upfront treatment of neuroblastoma, though these studies included children with low-stage, intermediaterisk disease and imaging did not consistently include sensitive ${ }^{123} \mathrm{I}$ MIBG scans $(35,36)$. Possible reasons for the low major response rate observed in neuroblastoma patients in our study could include a high disease burden at time of treatment (median pretherapy ${ }^{123} \mathrm{I}-$ MIBG score of 9) and a high proportion (74\%) of patients treated after multiple relapses, with a median of 3 relapses before treatment with ${ }^{131} \mathrm{I}-\mathrm{MIBG}$ plus arsenic trioxide. Furthermore, outcomes were even worse in patients with progressive disease who commenced therapy immediately before study entry (further progressive disease in $75 \%$ ), suggesting that ${ }^{131}$ I-MIBG therapy should be initiated only after disease has been stabilized with other modalities such as salvage chemotherapy.

Patients with refractory and relapsed metastatic neuroblastoma are considered to have a poor prognosis $(37,38)$. Although we observed few objective responses to therapy, a higher than expected number of neuroblastoma patients treated in our study (37\% [7/19]) are long-term survivors, although all but one have residual MIBGavid disease. The survivors include 3 patients treated at first relapse. Since 17 of 19 patients received further therapies, including 3F8, dissecting out the possible role of ${ }^{131} \mathrm{I}-\mathrm{MIBG}$ plus arsenic trioxide to their improved survival is impossible. 
The natural history of MP is often marked by prolonged remissions even without any anticancer therapy (39). Therefore, the contribution of ${ }^{131}$ I-MIBG plus arsenic trioxide to the longterm progression-free status of the two treated patients is unclear. Nevertheless, for both patients, the current progression-free intervals are significantly $(10 \times)$ higher than the time from prior therapy to relapse.

Extensive blood time-activity data were successfully collected and analyzed in 16 patients, with uniformly excellent fitting of biexponential functions to these data. On the basis of this analysis, the total absorbed dose to blood averaged only $46 \mathrm{cGy}$, well below myeloablative doses. This finding is consistent with the rapid initial clearance of ${ }^{131} \mathrm{I}-\mathrm{MIBG}$, with $87 \%$ of the blood-borne activity being cleared and a biologic half-time of $1.37 \mathrm{~h}$ on average. It is somewhat unexpected that these dose estimates would result in grade 3 or 4 bone marrow toxicity. However, all patients had been heavily treated beforehand with chemotherapy. An additional contribution to toxicity could be bone marrow involvement with neuroblastoma. Similar severe myelosuppression has been reported in all other studies using ${ }^{131} \mathrm{I}-\mathrm{MIBG}$ doses of $444 \mathrm{MBq} / \mathrm{kg}$ or higher.

\section{CONCLUSION}

High-dose ${ }^{131} \mathrm{I}-\mathrm{MIBG}$ plus the radiosensitizer arsenic trioxide was well tolerated in patients who had a substantial disease burden and had received heavy prior treatment. Antineuroblastoma activity was modest and approximated that observed in similar patient populations treated with high-dose ${ }^{131}$ I-MIBG with or without other radiosensitizers.

\section{DISCLOSURE}

The costs of publication of this article were defrayed in part by the payment of page charges. Therefore, and solely to indicate this fact, this article is hereby marked "advertisement" in accordance with 18 USC section 1734 . No potential conflict of interest relevant to this article was reported.

\section{ACKNOWLEDGMENTS}

We thank Rodney Prosser and the team at Nuclear Diagnostic Products for assisting with radiolabeling protocols and methods, Dr. Peter Smith-Jones for quality control, Samantha Leyco for data management, and Joe Olechnowicz for editorial input. We also thank Amabella Lindo, Louise Harris, and the radiopharmacy, radiation safety, and pediatric nursing teams at Memorial Sloan Kettering Cancer Center for dispensing and facilitating the administration of ${ }^{131} \mathrm{I}$-MIBG.

\section{REFERENCES}

1. Wieland DM, Wu J, Brown LE, Mangner TJ, Swanson DP, Beierwaltes WH. Radiolabeled adrenergic neuron-blocking agents: adrenomedullary imaging with [131I]iodobenzylguanidine. J Nucl Med. 1980;21:349-353.

2. Modak S, Cheung NK. Neuroblastoma: therapeutic strategies for a clinical enigma. Cancer Treat Rev. 2010;36:307-317.

3. Kushner BH. Neuroblastoma: a disease requiring a multitude of imaging studies. J Nucl Med. 2004;45:1172-1188.

4. Wilson JS, Gains JE, Moroz V, Wheatley K, Gaze MN. A systematic review of ${ }^{131}$ I-meta iodobenzylguanidine molecular radiotherapy for neuroblastoma. Eur $J$ Cancer. 2014;50:801-815.
5. Matthay KK, Quach A, Huberty J, et al. Iodine-131-metaiodobenzylguanidine double infusion with autologous stem-cell rescue for neuroblastoma: a New Approaches to Neuroblastoma Therapy phase I study. J Clin Oncol. 2009;27: 1020-1025.

6. Kang TI, Brophy P, Hickeson M, et al. Targeted radiotherapy with submyeloablative doses of ${ }^{131} \mathrm{I}-\mathrm{MIBG}$ is effective for disease palliation in highly refractory neuroblastoma. J Pediatr Hematol Oncol. 2003;25:769-773.

7. van Hulsteijn LT, Niemeijer ND, Dekkers OM, Corssmit EP. ${ }^{131}$ I-MIBG therapy for malignant paraganglioma and phaeochromocytoma: systematic review and meta-analysis. Clin Endocrinol (Oxf). 2014;80:487-501.

8. Streby KA, Shah N, Ranalli MA, Kunkler A, Cripe TP. Nothing but NET: a review of norepinephrine transporter expression and efficacy of I-mIBG therapy. Pediatr Blood Cancer. 2015;62:5-11.

9. Matthay KK, DeSantes K, Hasegawa B, et al. Phase I dose escalation of 131 Imetaiodobenzylguanidine with autologous bone marrow support in refractory neuroblastoma. J Clin Oncol. 1998;16:229-236.

10. Matthay KK, Tan JC, Villablanca JG, et al. Phase I dose escalation of iodine131-metaiodobenzylguanidine with myeloablative chemotherapy and autologous stem-cell transplantation in refractory neuroblastoma: a New Approaches to Neuroblastoma Therapy Consortium Study. J Clin Oncol. 2006;24: 500-506.

11. Mastrangelo S, Tornesello A, Diociaiuti L, et al. Treatment of advanced neuroblastoma: feasibility and therapeutic potential of a novel approach combining 131-I-MIBG and multiple drug chemotherapy. Br J Cancer. 2001;84: 460-464.

12. DuBois SG, Chesler L, Groshen S, et al. Phase I study of vincristine, irinotecan, and ${ }^{131}$ I-metaiodobenzylguanidine for patients with relapsed or refractory neuroblastoma: a New Approaches to Neuroblastoma Therapy trial. Clin Cancer Res. 2012;18:2679-2686.

13. McCluskey AG, Boyd M, Pimlott SL, Babich JW, Gaze MN, Mairs RJ. Experimental treatment of neuroblastoma using $\left[{ }^{131} \mathrm{I}\right]$ meta-iodobenzylguanidine and topotecan in combination. Br J Radiol. 2008;81(suppl):S28-S35.

14. More SS, Itsara M, Yang X, et al. Vorinostat increases expression of functional norepinephrine transporter in neuroblastoma in vitro and in vivo model systems. Clin Cancer Res. 2011;17:2339-2349.

15. Karlsson J, Ora I, Porn-Ares I, Pahlman S. Arsenic trioxide-induced death of neuroblastoma cells involves activation of Bax and does not require p53. Clin Cancer Res. 2004;10:3179-3188.

16. Gesundheit B, Malach L, Or R, Hahn T. Neuroblastoma cell death is induced by inorganic arsenic trioxide $\left(\mathrm{As}_{2} \mathrm{O}_{3}\right)$ and inhibited by a normal human bone marrow cell-derived factor. Cancer Microenviron. 2008;1:153-157.

17. Chiu HW, Lin JH, Chen YA, Ho SY, Wang YJ. Combination treatment with arsenic trioxide and irradiation enhances cell-killing effects in human fibrosarcoma cells in vitro and in vivo through induction of both autophagy and apoptosis. Autophagy. 2010;6:353-365.

18. Ning S, Knox SJ. Optimization of combination therapy of arsenic trioxide and fractionated radiotherapy for malignant glioma. Int J Radiat Oncol Biol Phys. 2006;65:493-498.

19. Ning S, Knox SJ. Increased cure rate of glioblastoma using concurrent therapy with high dose radiation and arsenic trioxide [abstract]. Int J Radiat Oncol Biol Phys. 2003;57(suppl):S257.

20. Liu H, Tao X, Ma F, Qiu J, Wu C, Wang M. Radiosensitizing effects of arsenic trioxide on MCF-7 human breast cancer cells exposed to 89 strontium chloride. Oncol Rep. 2012;28:1894-1902.

21. Lai YL, Chang HH, Huang MJ, et al. Combined effect of topical arsenic trioxide and radiation therapy on skin-infiltrating lesions of breast cancer: a pilot study. Anticancer Drugs. 2003;14:825-828.

22. Kai T, Kimura H, Shiga Y, Ogawa K, Sato H, Maruyama Y. Recurrent extramedullary relapse of acute promyelocytic leukemia after allogeneic stem cell transplantation: successful treatment by arsenic trioxide in combination with local radiotherapy. Int J Hematol. 2006;83:337-340.

23. Keung YK, Lyerly ES, Powell BL. Radiation recall phenomenon associated with arsenic trioxide. Leukemia. 2003;17:1417-1418.

24. Abla O, Ribeiro RC. How I treat children and adolescents with acute promyelocytic leukaemia. Br J Haematol. 2014;164:24-38.

25. Fox E, Razzouk BI, Widemann BC, et al. Phase 1 trial and pharmacokinetic study of arsenic trioxide in children and adolescents with refractory or relapsed acute leukemia, including acute promyelocytic leukemia or lymphoma. Blood. 2008; 111:566-573.

26. Cohen KJ, Gibbs IC, Fisher PG, Hayashi RJ, Macy ME, Gore L. A phase I trial of arsenic trioxide chemoradiotherapy for infiltrating astrocytomas of childhood. Neuro-Oncol. 2013;15:783-787. 
27. Brodeur GM, Pritchard J, Berthold F, et al. Revisions of the international criteria for neuroblastoma diagnosis, staging, and response to treatment. J Clin Oncol. 1993;11:1466-1477.

28. Messina JA, Cheng SC, Franc BL, et al. Evaluation of semi-quantitative scoring system for metaiodobenzylguanidine (mIBG) scans in patients with relapsed neuroblastoma. Pediatr Blood Cancer. 2006;47:865-874.

29. Naranjo A, Parisi MT, Shulkin BL, et al. Comparison of ${ }^{123}$ I-metaiodobenzylguanidine (MIBG) and ${ }^{131}$ I-MIBG semi-quantitative scores in predicting survival in patients with stage 4 neuroblastoma: a report from the Children's Oncology Group. Pediatr Blood Cancer. 2011;56:1041-1045.

30. Modak S, Pandit-Taskar N, Kushner BH, et al. Transient sialoadenitis: a complication of ${ }^{131}$ I-metaiodobenzylguanidine therapy. Pediatr Blood Cancer. 2008;50:1271-1273.

31. Hickeson MP, Charron M, Maris JM, et al. Biodistribution of post-therapeutic versus diagnostic ${ }^{131} \mathrm{I}-\mathrm{MIBG}$ scans in children with neuroblastoma. Pediatr Blood Cancer. 2004;42:268-274.

32. DuBois SG, Groshen S, Park JR, et al. Phase I study of vorinostat as a radiation sensitizer with ${ }^{131} \mathrm{I}$-metaiodobenzylguanidine $\left({ }^{131} \mathrm{I}-\mathrm{MIBG}\right)$ for patients with relapsed or refractory neuroblastoma. Clin Cancer Res. 2015;21:2715-2721.

33. French S, DuBois SG, Horn B, et al. ${ }^{131}$ I-MIBG followed by consolidation with busulfan, melphalan and autologous stem cell transplantation for refractory neuroblastoma. Pediatr Blood Cancer. 2013;60:879-884.
34. Yanik GA, Villablanca JG, Maris JM, et al. ${ }^{131}$ I-metaiodobenzylguanidine with intensive chemotherapy and autologous stem cell transplantation for high-risk neuroblastoma: a New Approaches to Neuroblastoma Therapy (NANT) phase II study. Biol Blood Marrow Transplant. 2015;21:673681.

35. Mastrangelo S, Rufini V, Ruggiero A, Di Giannatale A, Riccardi R. Treatment of advanced neuroblastoma in children over 1 year of age: the critical role of ${ }^{131} \mathrm{I}$-metaiodobenzylguanidine combined with chemotherapy in a rapid induction regimen. Pediatr Blood Cancer. 2011;56:10321040 .

36. de Kraker J, Hoefnagel KA, Verschuur AC, van Eck B, van Santen HM, Caron HN. Iodine-131-metaiodobenzylguanidine as initial induction therapy in stage 4 neuroblastoma patients over 1 year of age. Eur J Cancer. 2008;44:551556.

37. Cole KA, Maris JM. New strategies in refractory and recurrent neuroblastoma: translational opportunities to impact patient outcome. Clin Cancer Res. 2012;18:24232428.

38. Maris JM, Hogarty MD, Bagatell R, Cohn SL. Neuroblastoma. Lancet. 2007;369:21062120.

39. Fliedner SM, Lehnert H, Pacak K. Metastatic paraganglioma. Semin Oncol. 2010;37:627-637. 